\title{
Remote Sensing of the Coastal Ecosystems
}

\author{
Palanisamy Shanmugam* \\ Department of Ocean Engineering, Indian Institute of Technology Madras, Chennai 600036, India
}

\section{Introduction}

The coastal ecosystems comprised of biological, physical and chemical components, are indispensable to life on our planet and support the livelihood of people living and depending on coastal resources. These ecosystems are one of the most threatened but mostly populated landscapes in the world, which can no longer provide their biological functions and regulate services that sustain coastal economic production and livelihoods [1]. Thus, there is a pressing need for plans to address issues such as protection and sustainable use of coastal ecosystems. It is also a major concern of international organizations, including the Food and Agricultural organization (FAO), International Union for Conservation of Nature (IUCN), the UN Commission on Sustainable Development (CSD), Ramsar Convention of Wetlands and the Convention on Biological Diversity. It thus becomes very essential for maintenance and management of ecosystems, such as wetlands, mangrove swamps, salt marshes, estuaries, bay, and coral reefs that are home to many different types of plants and animals and support human needs. The ecosystem approach is a strategy for the integrated management of land, water and living resources that provides sustainable delivery of ecosystem services in an equitable way, thus its management is to be designed and executed in an adaptive, learningbased process that applies the principles of the scientific method to the process of management [2].

Coastal zones are the site of complex natural systems where intense interactions occur between the hydrosphere, lithosphere, and the atmosphere, which meet and interact, forming interconnected systems [3]. It is to be noted that healthy coastal ecosystems provide valuable services such as food security, resources for economic growth, recreation alongside tourism, coastline protection and crucial reservoirs of biodiversity [2]. Global climatic and oceanographic events contribute to sea level rise, severe storm events, coastal erosion, and sea surface temperature, all of which can harm coastal ecosystems. In addition to the direct impacts coastal areas such as barrier islands, beaches, and wetlands are highly sensitive to sea-level changes. Rising seas will intensify coastal flooding and increase the erosion of beaches, and wetlands, as well as threaten jetties, piers, seawalls, harbors, and waterfront property [4]. Increasing stress keeps accelerating human interventions that impact natural coastal ecosystem processes and it becomes paramount importance for environmental monitoring and assessment in order to manage and protect these sensitive areas more effectively through continues and coordinated observations. Understanding of regional and global-scale variability of coastal ecosystem has been limited by in-situ sampling confined to point measurements. Remote sensing technique is the best identified alternatives and the most cost-effective method for providing temporally resolved synoptic views of coastal zone region over long periods of time.

Coastal ecosystems reveal tremendous variations in aerial extent, spatial complexity, and temporal variability, thus required to be observed with spatial, spectral, and temporal resolutions from both satellites and aircrafts. Some of the ecosystem health indicators that can be observed by remote sensors include wetland loss and fragmentation, wetland biomass change, vegetation cover, deforestation of mangroves, percentage of impervious watershed area, buffer degradation, and changes in hydrology, changes in shoreline and high water line, erosion and accretion, harmful algal blooms, water turbidity, chlorophyll concentration, eutrophication level, salinity and temperature [4-12]. Protecting coastal ecosystems requires the ability to monitor changes in their biophysical features and controlling processes at high spatial and temporal resolutions. At present satellite and airborne remote sensors can map and measure coastal ecosystems and their changes cost effectively at suitable scales and resolutions, minimizing the need for extensive field and ship measurements [4].

This special issue demonstrates the use of cost-effective remote sensing technologies and related field observation techniques for evaluating, monitoring and sustainable management of coastal ecosystems. This issue evaluates the major types of global coastal ecosystems, discusses the major benefits and possible challenges of using remote sensing geophysical technologies. It covers a variety of remote sensing techniques, such as multispectral, hyperspectral imaging spectrometers, thermal infrared sensors, synthetic aperture radars, scatterometers, altimeters and LIDAR. It emphasizes not only the integration of data acquired from these sensors on various types space-borne and air-borne platforms to provide sufficient spatial, spectral, radiometric and temporal resolutions, but also the incorporation of a reliable field data collection approach to acquire sufficient in-situ measurements that are used to calibrate and validate the remotely sensed information.

\section{Content of the Special Issue}

This special issue is targeted for scientists, managers and researchers interested in using remote sensing in the study or management of coastal ecosystem and would serve as an important reference source for the scientific community.

This special issue consolidates various papers that address diverse topics of coastal ecosystem [1-12], such as:

- Monitoring coastal wetlands and watersheds by studying the impact of land runoff on estuarine and coastal ecosystems, including watershed models, hydrodynamic models, water quality models, and living resource models

- Examine wetland changes and land cover trends, such as impact of rising sea levels and hurricanes on wetlands, by means of analyzing time series of remotely sensed imagery.

*Corresponding author: P. Shanmugam, Ocean Optics and Imaging Group, Department of Ocean Engineering, Indian Institute of Technology Madras, Chennai, India, Tel: 91-44-2257-4818; E-mail: pshanmugam@iitm.ac.in

Received December 22, 2012; Accepted December 26, 2012; Published December 29, 2012

Citation: Shanmugam P (2013) Remote Sensing of the Coastal Ecosystems. J Geophys Remote Sensing S2:e001. doi:10.4172/2169-0049.S2-e001

Copyright: @ 2013 Shanmugam P. This is an open-access article distributed under the terms of the Creative Commons Attribution License, which permits unrestricted use, distribution, and reproduction in any medium, provided the original author and source are credited. 
- Understanding shoreline topography and bathymetry, since topographic and hydrographic information are basic elements in studies of near shore geomorphology, hydrology, and sedimentary processes.

- Mapping submerged aquatic vegetation, coral reefs, and general bottom characteristics becausedecline of coral reefs is closely linked to human activity, as they thrive in a narrow range of environmental conditions and are very sensitive to small changes in temperature, light, water quality, and hydrodynamics.

- Monitoring of ocean chlorophyll since biological productivity can be estimated by measuring the chlorophyll-a concentration.

- Observing eutrophication and hazardous algal blooms in view of the fact that high concentrations of nutrients exported from agriculture or urban cover in coastal watersheds, or produced by coastal upwelling, are causing algal blooms in many estuaries and coastal waters.

- Supervising sea surface temperature (SST) and sea surface salinity (SSS) because they are necessary for estimating the source of heat at the air-sea boundary. Sea surface temperature and salinity are also important input data for estimating the steric component of the sea level, which is important for coastal studies. SSS is critical for determining the global water balance, for understanding ocean currents, and for estimating evaporation rates.

- Detection and tracking of oil spill, so as to limit the damage by a spill and facilitate containment and cleanup efforts. Also the environmental engineers and managers and other responsible scientific community obtain information on spill location, size and extent of the spill, direction and speed of oil movement, and wind, current, and wave information for predicting future oil drift and dispersion.

- Studying physical offshore processes as the currents and waves that strongly affect coastal ecosystems, which is an extremely dynamic environment.

\section{Perspectives}

By virtual of their position, coastal areas are highly dynamic and located at the interface between terrestrial and aquatic ecosystems, which are one of the most challenging targets for environmental remote sensing. This issue presents the latest developments in the use of remote sensing and geospatial technologies for characterizing coastal wetlands and watersheds, shorelines, coastal waters, submerged aquatic vegetation, benthic habitats, and coral reefs. Case studies of the operational use of remote sensing in evaluating changes, ecosystem monitoring and management are dealt with. The different applications in this issue are representative of the interdisciplinary, multi-scale studies taking advantage of remote-sensing capacities for coastal science, management and conservation. Recently launched satellites are providing the means for more accurately detecting changes in coastal ecosystem health, including biological productivity and habitat quality. Thermal IR imagers and new satellite microwave radiometers are able to map sea surface temperatures, salinity, and soil moisture. Scatterometers, altimeters, and SAR data are providing more accurate information on sea surface winds, elevation, currents, wave fields and oil slicks and oil spill drift and dispersion which can be used in the models to predict their impacts on coastal ecosystems. Even such voluminous data is insufficient, in dealing with problems related to the coastal ecosystem. However, the above perspectives give tremendous scope for practical experimentation to take up research related to remote sensing of coastal ecosystems. Paper presented in this special issue is a reflection of tedious and worthwhile data collected at various time steps.

\section{References}

1. Wattage $P$ (2011) Valuation of ecosystem services in Coastal Ecosystems: Asian and European Perspectives. The United Nations Environment Programme, Nairobi, Kenya.

2. UNEP (2011) Taking Steps toward Marine and Coastal Ecosystem-Based Management-An Introductory Guide.

3. Wilches $G$ (1995) Disasters and the environment. (2nd Edn).

4. Klemas $\vee(2011)$ Remote sensing techniques for studying coastal ecosystems: an overview. Journal of Coastal Research 27: 2-17.

5. Lathrop RG, Cole MB, Showalter RD (2000) Quantifying the habitat structure and spatial pattern of New Jersey (U.S.A.) salt marshes under different management regimes. Wetlands Ecology and Management 8: 163-172.

6. Richardson LL, LeDrew EF (2006) Remote Sensing of Aquatic Coastal Ecosystem Processes: Science and Management Applications. Remote Sensing and Digital Image Processing 9: 330.

7. Shanmugam P, Ahn YH, Sanjeevi S (2006) A comparison of the classification of wetland characteristics by linear spectral mixture modeling and traditional hard classifiers on multispectral remotely sensed imagery in southern India. Ecological Modelling 194: 379-394.

8. Shanmugam P, Ahn YH, Sanjeevi S, Manjunath AS (2003) Integration of ERS2 SAR and IRS- 1D LISS-III for improved coastal wetland mapping. Korean Journal of Remote Sensing 19: 351-361.

9. Shanmugam P, Ahn YH, Ram PS (2008) SeaWiFS sensing of hazardous algal blooms and their underlying physical mechanisms in shelf-slope waters of the Northwest Pacific during summer. Remote Sensing of Environment 112: 32483270.

10. Shanmugam $P$ (2011) A new bio-optical algorithm for the remote sensing Journal of Geophysical Research 116: 12.

11. Ahn YH, Shanmugam P, Moon JE, Ryu JH (2008) Satellite remote sensing of a low-salinity water plume in the East China Sea. Annales Geophysicae 26 2019-2035.

12. Ahn YH, Shanmugam P, Gallegos S (2004) Evolution of suspended sediment patterns in the East China and Yellow Seas. Journal of the Korean Society of Oceanography 39: 26-34. 